Produto \& Produção, vol. 15 n.2, p. 24-45, jun. 2014

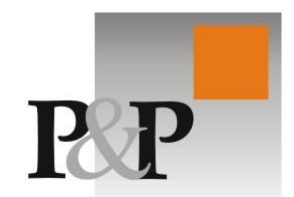

RECEBIDO EM 16/04/2013. ACEITO EM 20/05/2014.

\title{
Análise de decisão multicritério aplicada na seleção de investimento em armazenagem de soja em grão
}

\author{
Patrícia Dias Barboza \\ Universidade de São Paulo - USP \\ Departamento de Engenharia de Sistemas Logísticos \\ patriciadbarboza@gmail.com
}

\author{
José Geraldo Vidal Vieira \\ Universidade Federal de São Carlos - USP \\ Departamento de Engenharia de Produção e Centro de Ciências e Tecnologia para a \\ Sustentabilidade \\ jose-vidal@ufscar.br
}

\section{RESUMO}

Esta pesquisa apresenta uma literatura dos principais atributos que compõem uma decisão de armazenagem com o objetivo de construir um modelo que auxilie o processo de tomada de decisão para a escolha de armazém de soja em grão sob a visão de uma trading. A abordagem multicritério se faz necessária devido à complexidade envolvida nos tipos de armazenagem. O método utilizado é baseado na Teoria de Valor Multi-Atributo (MAVT) e foi construído no software V.I.S.A. para eleger um projeto hipotético dentre as alternativas disponíveis. Os pesos dos critérios consistem numa decisão em grupo que foi obtida a partir da aplicação de questionários a onze profissionais do setor. Os resultados mostraram que os atributos mais relevantes se referem à perspectiva de aumento de mercado e preocupação com a diminuição de custos logísticos. Por outro lado, os atributos qualidade e capacidade estática foram os menos relevantes. Conclui-se que o modelo se mostrou coerente em relação ao perfil das alternativas criadas e recomenda-se a sua utilização por decisores de uma trading como parte do processo de tomada de decisão.

Palavras-chave: Tomada de Decisão Multicritério, MAVT, Armazenagem de Soja.

\begin{abstract}
This research provide a literature review of the main attributes in decision-making process of bulk warehouse for soybeans in order to build a model of this specific process under the vision of a trading company. A multicriteria approach is necessary due to the complexity involved in the selection of the warehouse. The method used is based on the Theory of Multi-Attribute Value (MAVT) and was built in software VISA to choose a hypothetic project among the available alternatives. The weights of each criteria were compound of a group decision that was obtained from the questionnaires of eleven professionals. The results have showed that the main attributes refer to perspective of an increase in market share and concerning to decrease in logistical costs. On the other hand, the attributes less relevants were quality and static capacity. It is concluded that the model is consistent over the profile among created alternatives and it is recommended as part of decision-making process of a trading company.
\end{abstract}


Keywords: Multicriteria Making-decision; MAVT, Soybean Warehouse.

\section{Introdução}

A importância econômica da cadeia da soja no cenário nacional tende a se manter com a previsão otimista de aumento da produção para os próximos anos no Brasil. As estimativas para soja em grão indicam uma produção de 86,5 milhões de toneladas em 2020/2021. Esta projeção prevê um aumento de 17,8 milhões de toneladas em relação ao que o Brasil produziu na safra de 2010/2011, com taxa de crescimento anual prevista para a produção de $2,3 \%$ neste período de projeção (MAPA, 2011). Por outro lado, as taxas projetadas para consumo nacional e para o mercado de exportação de soja são, respectivamente, $1,9 \%$ e $3,2 \%$; ou seja, uma previsão de aumento do consumo e comercialização.

Diante desse cenário, o estudo da logística de armazenagem e distribuição de soja, frente às perspectivas do setor para o atendimento à demanda, se torna relevante na medida em que permite mostrar as lacunas de pesquisa e, ao mesmo, os desafios dessa logística. Esta pesquisa foca na escolha de projetos para armazenagem de soja em grão, baseada na avaliação de multicritérios quantitativos como análise de viabilidade econômica de projetos e qualitativos, por exemplo, infraestrutura e aspectos regionais relacionados à demanda, capacidade agrícola e contribuição social.

Gallardo et al. (2010) salientam que a atual capacidade estática de armazenagem1 no Brasil já se encontra inferior ao nível recomendado pela FAO (Fundação da Organização das Nações Unidas para a Agricultura e a Alimentação), em cerca de 70 Mt. Além disso, o setor não responde ao crescimento acentuado da produção agrícola e nem às mudanças na distribuição geográfica da produção. A estocagem na própria unidade produtora no Brasil é de apenas $15 \%$ da capacidade estática total, contra $85 \%$ na Austrália, $65 \%$ nos EUA, 50\% em média na Europa, $40 \%$ na Argentina e $35 \%$ no Canadá. Portanto, é evidente a necessidade da implantação de armazéns próximos às unidades produtoras. Além disso, a escolha eficiente de um sistema de armazenagem permitiria criar condições para o equilíbrio entre oferta e demanda de serviços de transporte em picos de safras e, consequentemente, a redução de fretes (NOGUEIRA JUNIOR \& TSUNECHIRO, 2005), portanto de natureza estratégica.

Segundo Frederico (2010), a questão da escolha de armazenagem sob a visão de uma trading2 é tão estratégico, que os novos agentes financeiros, que entraram recentemente no comércio mundial de grãos, já estão adquirindo silos nas principais regiões produtoras. Os silos podem oferecer a esses investidores novas maneiras de ganhar dinheiro, porque eles seriam capazes de comprar e vender os grãos de fato, e não apenas os seus derivativos financeiros, além da oportunidade de venda futura.

O objetivo do artigo é propor um modelo multicritério para escolha de alternativas de armazenagem de soja em grão sob a visão de uma trading. $\mathrm{O}$ estado da arte desta pesquisa se baseia no levantamento dos principais critérios que compõem a decisão de armazenagem. Portanto, a contribuição desta pesquisa se baseia na construção de uma árvore de decisão com base na revisão de literatura e na definição de uma escala de prioridades desses atributos de valor segundo as preferências dos decisores. Ressalta-se que atributo será usado como sinônimo de critério.

A tomada de decisão para a escolha das alternativas de armazém por uma trading não é simples. Pois, basear-se em somente um critério, por exemplo, o custo, é insuficiente e, critérios conflitantes como custo e retorno do investimento, e qualitativos devem ser também considerados. Daí um dos principais motivos para a escolha do método multicritério e não somente a escolha de critérios quantitativos, em que a aplicação de métodos otimizantes seria mais adequada. Portanto, a presente pesquisa se justifica à medida que a escolha e a manutenção de um sistema de armazenamento eficiente, seja este um armazém graneleiro, silo metálico, silo em concreto, silo bag ou armazém convencional (DEVILLA, 2004), leve em conta múltiplos critérios para a sua escolha, entre eles: localização e transporte, infraestrutura local e aspectos da região produtora, viabilidade econômica, atendimento aos requisitos técnicos para construção dos armazéns, capacidade e eficiência operacional e mercado.

1 Quantidade de grãos de soja que pode realizar-se de uma só vez dentro de uma unidade armazenadora.

2 Empresa que opera no comércio exterior como importadora e exportadora para outras empresas do setor, atuando tanto na área comercial quanto na área operacional. 


\section{Cenário Brasileiro do Armazenamento de Soja}

\subsection{Fluxo da soja}

A perecibilidade e sazonalidade da produção agrícola demandam um sistema de armazenagem em pontos de distribuição (propriedades rurais, silos, portos e fábricas de esmagamento) para o escoamento da colheita (NOGUEIRA JUNIOR \& TSUNECHIRO, 2005). E por isso, a armazenagem desempenha um papel fundamental na manutenção do equilíbrio entre oferta e demanda e na continuidade do fluxo ao longo da cadeia.

O fluxo da soja em grão no Brasil (vide Figura 1) tem seu início com a retirada do produto das fazendas de caminhão. A soja tem dois destinos: Mercado Interno com a finalidade de abastecer plantas de esmagamento ou Mercado Externo, onde a soja será exportada in natura (OJIMA, 2006).

A soja destinada ao mercado interno pode seguir direto para as unidades de armazenagem das plantas e/ou para silos (objeto desta investigação) e depois para as fábricas. Devido à política fiscal vigente, a incidência de ICMS inviabiliza, na maioria dos casos, movimentações interestaduais, ou seja, é mais vantajoso que a soja seja processada em seu estado de origem (SILVA \& MENEZES, 2008).

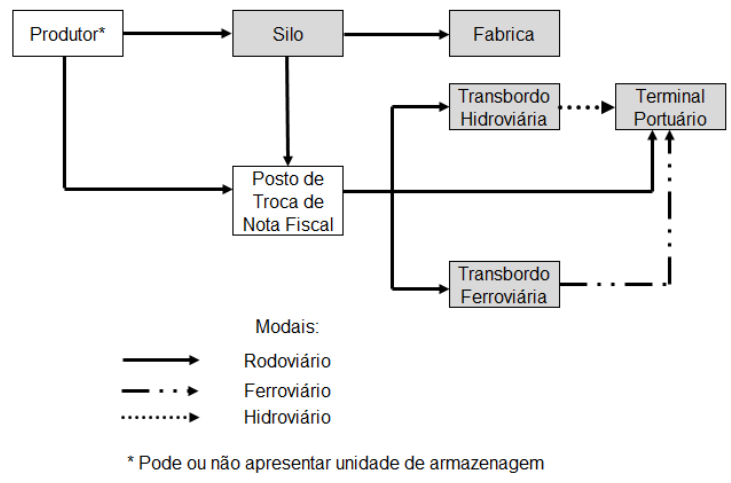

Figura 1 - Mapeamento do fluxo da soja em grão

Fonte: Elaborado pelos autores com base em Silva \& Menezes (2008); Ojima (2006) e Passin (2007)

Quando a soja é destinada à exportação, são utilizados transbordos ferroviários e hidroviários que compõem os corredores de escoamento de soja e são importantes para diminuir os custos com o transporte até os portos. Como estes estados produtores não são os mesmos onde se localizam os principais portos existe a necessidade de passar em Postos de Troca de Nota Fiscal para regulamentação da documentação que acompanha a mercadoria (CONAB, 2006; 2007).

\subsection{Fatores que influenciam a gestão e escolha de armazenagem de soja}

No Brasil, os armazéns podem ser classificados em quatro categorias sob o critério da localização, tais como: zonas portuárias, áreas urbanas, áreas rurais externas à fazenda e áreas internas às unidades produtoras (GALLARDO, 2010). Como apenas 15\% dos armazéns se encontram internamente às unidades produtoras, a capacidade dos produtores de vender seus produtos a melhores preços na época de entressafra é limitada. Se um lado o armazenamento da produção permite a escolha do melhor momento para a sua comercialização, buscando preços mais atrativos, de outro exige sacrifícios financeiros. A imobilização de recursos pelo investimento em infraestrutura de armazenagem, custos de conservação do produto e abdicação de um possível ganho financeiro com a aplicação dos recursos que seriam conseguidos com a venda desses produtos são exemplos desses sacrifícios (ZANCHET, 2004).

A estratégia competitiva do Brasil na exportação dos produtos do complexo da soja se baseia principalmente na redução do custo de produção como forma de aumentar a margem de 
comercialização. Porém, a gestão da armazenagem por sofrer influência de muitos fatores como seguem.

Há uma constante oscilação nos preços, dos produtos agrícolas, geralmente obedecendo às pressões da elevada oferta de produtos nos períodos de safra e escassez nos de períodos de entressafra, como no caso da soja (OJIMA \& YAMAKAMI, 2006). Como tentativa para se protegerem dessas oscilações, os produtores agrícolas "delegam" ou entregam a sua produção às tradings e agroindústrias numa das seguintes modalidades: 1) mercado spot consiste na entrega da produção com a imediata efetivação da venda; tudo é esporádico e não há compromissos com futuras transações; 2) contratos a termo ou "produto verde", que consiste no contrato firmado, para a entrega futura da produção com preço previamente fixado; ou seja, o objetivo deste contrato é garantir, por um lado, a entrega do produto pelo produtor e, de outro, o cumprimento do preço pelo agente, conforme estabelecido em contrato; ou, ainda, (3) a entrega da produção em depósito com preço a fixar (produção para futura comercialização ou retirada) (AFONSO, 2006). Como o preço da soja é formado no mercado internacional, por meio da Bolsa de Chicago, e grande parte da produção mundial de grãos se divide entre América do Norte e América do Sul, com épocas de safras distintas, os grupos internacionais buscam estarem presentes nas duas regiões (PINAZZA, 2007) e com isso um eficiente sistema de armazenagem é necessário.

Em relação à tributação, a Lei Kandir isentou o Imposto sobre Circulação de Mercadorias e Serviços (ICMS) sobre a exportação dos produtos básicos, incluindo a soja em grãos. Desde então, tornou-se mais vantajoso para as indústrias exportarem soja em grão diretamente, a partir dos estados produtores, ao invés de processar e armazenar a matéria-prima internamente. As características tributárias atuais também fomentam a importação de soja. Para uma indústria instalada no Paraná, é mais vantajoso importar soja do Paraguai, processá-la e, depois, exportar o farelo e o óleo, numa operação de draw back, do que percorrer uma distância equivalente e comprar soja, por exemplo, em Mato Grosso do Sul. No caso da compra em outro estado para posterior exportação dos derivados, a indústria enfrenta dificuldades para recuperar os créditos resultantes da incidência do ICMS (PINAZZA, 2007).

A participação das empresas multinacionais na coordenação das atividades do Sistema Agroindustrial (SAG) da soja na economia brasileira torna a sua análise um fator fundamental, tanto para o delineamento de estratégias individuais ou coletivas quanto para a elaboração de políticas públicas que venham a tornar eficiente a armazenagem de soja em grãos. A linha estratégica predominante é liderança em custos (baseada fortemente em economias de escala, busca de redução da capacidade ociosa, logística eficiente, inovação em processos), ao passo que no estágio de derivados predomina a diferenciação de produtos (com forte orientação para segmentação de mercados, promoção/marca e inovação de produtos), confirmando assim, sua "governança". De acordo com dados da Associação Brasileira das Indústrias de Óleos Vegetais (ABIOVE), as quatro principais esmagadoras de soja atuantes no Brasil são multinacionais e detêm 52,6\% de toda a capacidade de esmagamento instalada (PINAZZA, 2007).

Outro fator que influencia a armazenagem é a capacidade estática de armazenamento. A capacidade estática e a utilização do armazém são as informações que avaliam o potencial de volume que será armazenado no cálculo de viabilidade econômica do projeto. A capacidade estática de armazenagem pode ser definida como a quantidade de grãos que cabe de uma só vez confinada em uma unidade armazenadora (em toneladas) enquanto a utilização do armazém pode ser calculada pela quantidade de grãos que entrou e saiu de uma unidade armazenadora no período de um ano (capacidade dinâmica) divido pela capacidade do armazém (AZEVEDO et al., 2008)..

A partir da década de 1990, com a adoção de uma política de menor intervenção estatal, a capacidade estática de armazenamento permaneceu praticamente estável, enquanto a produção agrícola continuou a crescer. O Estado, principal financiador e armazenador até a década de 1980 começou a se desfazer das suas unidades armazenadoras. Na década de 1990, os maiores investimentos foram realizados pelas tradings, principalmente nos fronts agrícolas, devido ao interesse em ter acesso privilegiado e garantido aos grãos. A participação estatal, que representava a quase totalidade da capacidade de armazenamento existente na década de 1970, reduziu-se a apenas $5 \%$ em 2006 , contra $74 \%$ das entidades privadas e $21 \%$ das cooperativas. Sem o controle do sistema de armazenamento as empresas teriam um problema logístico que inviabilizaria a aquisição dos grãos. As formas de financiamento realizadas pelas empresas por meio da CPR (Cédula do Produtor Rural) 
somente são viabilizadas, na prática, devido à capacidade destas em estocar os grãos (FREDERICO, 2010).

Além desses fatores que influência a gestão de armazenagem de soja, outros fatores relacionados à escolha do armazém são apresentados a seguir, tais como: localização e transporte, infraestrutura e aspectos regionais, análise de viabilidade econômica, aspectos de engenharia, capacidade e eficiência operacional e aspectos de mercado. Esses fatores foram compilados a partir da revisão de literatura e serão apresentados a seguir. Alguns desses fatores são utilizados por agentes reguladores como MAPA (Ministério da Agricultura, Pecuária e Abastecimento) e CONAB (Companhia Nacional de Abastecimento) para uma a escolha adequada de armazenagem de soja em grãos.

\subsubsection{Localização e Transporte}

O fator "Localização e Transporte" tem por objetivo avaliar qual é o local que permitirá o melhor plano de movimentação fazenda-armazém e armazém-destino, ou seja, garantir o escoamento da maior quantidade de produto com os menores custos de transporte no tempo requerido pelo mercado para garantir a viabilidade econômica do projeto. Segundo Ballou (2006) a localização das instalações na rede é um importante problema de planejamento estratégico de logística e cadeia de suprimentos para grande parte das empresas. No caso da cadeia da soja no Brasil como a produção é grande e concentrada no período da colheita exige a localização de instalações múltiplas e o uso combinado de modais de transporte para escoamento.

A importância da localização na posição estratégica da empresa é enfatizada por Yang \& Lee (1997) devido ao seu impacto nos custos operacionais, velocidade e desempenho da entrega e flexibilidade para competir no mercado. De acordo com as especificidades de cada empresa, os objetivos podem ser baseados em uma das quatro principais vertentes: minimizar custo, orientar pela demanda, maximizar lucro ou posicionar segundo alguma oportunidade de mercado e meios disponíveis de transporte.

A movimentação rodoviária de soja apresenta um papel de destaque no transporte de granéis agrícolas, pois devido às condições de infraestrutura existentes é o caminhão que realiza o transporte das lavouras para o seu primeiro destino, geralmente, o armazém e, esta tarefa exige grandes volumes. Caixeta Filho et al. (2001) afirmam que a oferta de veículos não é suficiente para cobrir a demanda existente para movimentação da soja e outros produtos agrícolas, o que proporciona um aumento significativo dos fretes. Martins et al. (2008) destacam a importância do custeio como um dos critérios mais frequentemente utilizados de parametrização do desempenho nas cadeias de suprimentos. Explica que os transportes agregam custos diretamente referentes aos fretes pagos e, indiretamente, por meio de sua eficiência operacional que transborda para as demais atividades e operações da logística, segundo os inúmeros trade-offs com o composto logístico, tais como as decisões de centralização ou não dos estoques na cadeia, as políticas de armazenagem, o número, a localização e o tamanho das instalações logísticas, dentre outros.

\subsubsection{Infraestrutura e aspectos regionais}

O fator "infraestrutura e aspectos regionais" avalia a região na qual serão alocados os projetos em estudo sob três principais aspectos: agrícolas, sociais e sobre o tema deste estudo que é a demanda por armazenagem. Lacerda Filho et al. (2000) sugerem estimar com base em pelo menos cinco anos e para cada produto, a possibilidade de aumento de produtividade ou da produção pelo aumento da área plantada. Uma análise dos períodos de colheita, estabelecendo o início e o final de cada safra, com estimativas de quantidade colhida em cada mês também se faz necessário para caracterizar a região.

Análises de fluxos de carga e sazonalidade de armazenamento, custos de armazenagem e informações qualitativas sobre o mercado agrícola podem ser incorporados na avaliação desse fator. Estas informações podem ser obtidas pelo Siarma (Sistema de Informações de Armazenagem), que de maneira integrada com o SIFRECA, tem se mostrado essenciais ao dimensionamento de projetos logísticos voltados para os complexos agroindustriais.

\subsubsection{Análise de Viabilidade Econômica}


A análise de viabilidade econômica engloba dois importantes fatores: análise de investimento e análise de custos (DIAS e MALACO, 2010). Segundo Bataglin et al. (2012) a principal fase das decisões de investimentos em projetos de longo prazo consiste na utilização de métodos de avaliação econômica com vista em se apurar os resultados das aplicações de capital. A literatura é vasta em métodos para a mensuração de projetos. O método mais comum a ser utilizado nessa pesquisa é o valor presente líquido (VPL), definido como a soma algébrica dos valores descontados do fluxo de caixa a ele associado (CARBINATTO. 2003). Em outras palavras, é a diferença do valor presente das receitas menos o valor presente dos custos (NETO, 2008).

Para a aplicação do VPL a projetos ou ativos com risco, Carbinatto (2003) questiona duas premissas fundamentais: (a) fluxos de caixa incertos são substituídos pelo seu valor projetado, estimado no início da vida útil do projeto. Ainda, assume-se uma gerência passiva da empresa, sem revisão de decisões estratégicas. Desta forma, interpreta-se que as decisões implementadas não podem ser revistas, retirando a flexibilidade característica do gerenciamento de projetos e empresas. Segundo Trigeorgis (1993), a flexibilidade gerencial permite a capitalização de futuras oportunidades favoráveis à empresa ou a um determinado projeto; (b) as premissas para a taxa de desconto são sua definição e manutenção constante ao longo do tempo, dependendo exclusivamente do risco do projeto, também constante no decorrer do tempo. Há dois métodos básicos, entre outros, para definição da taxa de desconto (1) o Custo Médio Ponderado de Capital (WACC - Weighted Average Cost of Capital), aplicado para toda a empresa ou, em alguns casos, apenas para uma divisão específica; e (2) o Valor Presente Ajustado (APV - Adjusted Present Value), inicialmente proposto por Stewart C. Myers em 1974, e que considera riscos diferentes para cada componente do fluxo de caixa. De acordo com Hayes \& Garvin (1982), dada às deficiências do método do fluxo de caixa descontado, julgamentos e observações estratégicas subjetivas deveriam compor a base das decisões sobre projetos, sem, entretanto distorcer os métodos quantitativos aplicados.

Para a análise de custos, Ballou (2006) sugere que as decisões sobre estratégias logísticas devem ser baseados no arranjo entre os diferentes componentes logísticos: estrutura de instalações; processamento de pedidos; manutenção de informação; transporte; manutenção de estoques; e armazenagem e manuseio. Estas decisões são baseadas em análise de balanceamento entre os componentes para buscar menor custo total.

\subsubsection{Aspectos de engenharia}

Este fator é baseado na Instrução Normativa No 29, de 8 junho de 2011, que consolida todas as normas e procedimentos a serem adotados na implantação do Sistema Nacional de Certificação de Unidades Armazenadoras (MAPA, 2012). Este documento estabelece os requisitos técnicos obrigatórios ou recomendados para construção, instalação e funcionamento de estruturas de armazenamento visando a modernização do setor. Alguns desses requisitos são técnicos obrigatórios e outros recomendados para uma unidade armazenadora granel em ambiente natural, objeto de estudo desta pesquisa. Assim, a definição de localização será estabelecida previamente para a elaboração dos projetos de armazenagem que entrarão no processo de tomada de decisão de uma unidade armazenadora.

\subsubsection{Capacidade e eficiência operacional}

Este fator mede o potencial do projeto em garantir o alcance do objetivo do armazenamento que é guardar e preservar as características que os grãos apresentam após a colheita, diminuindo ao máximo as perdas, utilizando-se, da melhor maneira possível, as técnicas existentes (BROOKER et al., 1992; AZEVEDO et al., 2008). Este fator está diretamente relacionado à: capacidade estática (apresentada anteriormente), utilização do armazém (giros de estoque), eficiência dos sistemas e linhas de processamento e qualidade do produto.

Dois tipos de perdas podem ocorrer nos grãos numa unidade de armazenagem: perda física ou quebra e perda de qualidade. A perda por quebra ocorre quando o produto sofre uma perda de peso pelos danos mecânicos causados na movimentação, por animais e/ou insetos. Enquanto a perda de qualidade é aquela que ocorre quando as qualidades intrínsecas, essenciais do produto, são alteradas, principalmente, pela ação de fungos, umidade e temperatura, os quais causam fermentações, 
modificações organolépticas (alterações do gosto e cheiro natural do produto) e redução do valor nutritivo dos grãos (D’ARCE, 2012). As técnicas existentes para reduzir tais perdas são compostas pelos sistemas de limpeza, movimentação, secagem, aeração, termometria e higienização.

\subsubsection{Aspectos de mercado}

O entendimento de como o mercado da soja se comporta, assim como possíveis fatores que podem impactar na oferta e demanda são de extrema importância para sucesso de um projeto de armazenagem, já que a garantia de volume armazenado e margem de comercialização garantirá a viabilidade econômica da unidade armazenadora. Como já foi dito anteriormente, o destino da soja armazenada pode ser destinada tanto a uma empresa esmagadora (mercado interno) como exportação nos meses de entressafra.

Quando se analisa a estrutura de mercado procura-se medir o nível de concentração do mercado, avaliar se o mercado apresenta características de forte competição entre as empresas, ou se existem mecanismos de controle da demanda e/ou da oferta (SOUZA FILHO et al., 2007). Os mesmos autores sugerem alguns indicadores de concentração que podem ser construídos para compor a análise:

- número total de propriedades, empresas processadoras e intermediárias que participam do mercado interno e exportação;

- participação de pequenas, médias e grandes propriedades rurais na produção total;

- evolução do market-share das empresas líderes;

- área média das propriedades;

- descrição da evolução recente das fusões e incorporações de empresas;

- identificação das alterações na posição de algumas empresas de um ano para o outro.

Além disso, os autores sugerem para a composição da análise:

- caracterização das empresas líderes, procurando identificar a capacidade instalada de produção, o número de unidades de processamento, estocagem e preços, qualidade, transporte, direitos trabalhistas, direitos humanos, especialmente aquelas que são objeto de maior conflito.

- identificação das principais organizações, tais como associações de produtores, sindicatos, associações de empresas processadoras, organizações governamentais e seu papel na definição de políticas públicas ou privadas. Em especial, deve-se apontar seu campo de atuação e seu papel na coordenação do sistema.

\section{Metodologia}

A pesquisa proposta pode ser caracterizada como uma pesquisa aplicada (GIL, 2002), já que visa gerar conhecimentos a partir de uma tomada de decisão multicritério aplicada na escolha de alternativas de unidade de armazenagem (objeto desta pesquisa) de soja em grão, sob a visão de uma trading do setor.

O modelo (vide Figura 2) será elaborado com base na literatura e os pesos dos critérios e subcritérios que constituem uma árvore de decisão foram validados e ponderados por profissionais do setor através de um questionário (Apêndice A). As ponderações dos critérios e subcritérios foram agregadas para compor a decisão do grupo. Apesar de não ser um estudo de caso, um exemplo hipotético foi criado para validação do modelo com base no valor de decisão de uma trading. 


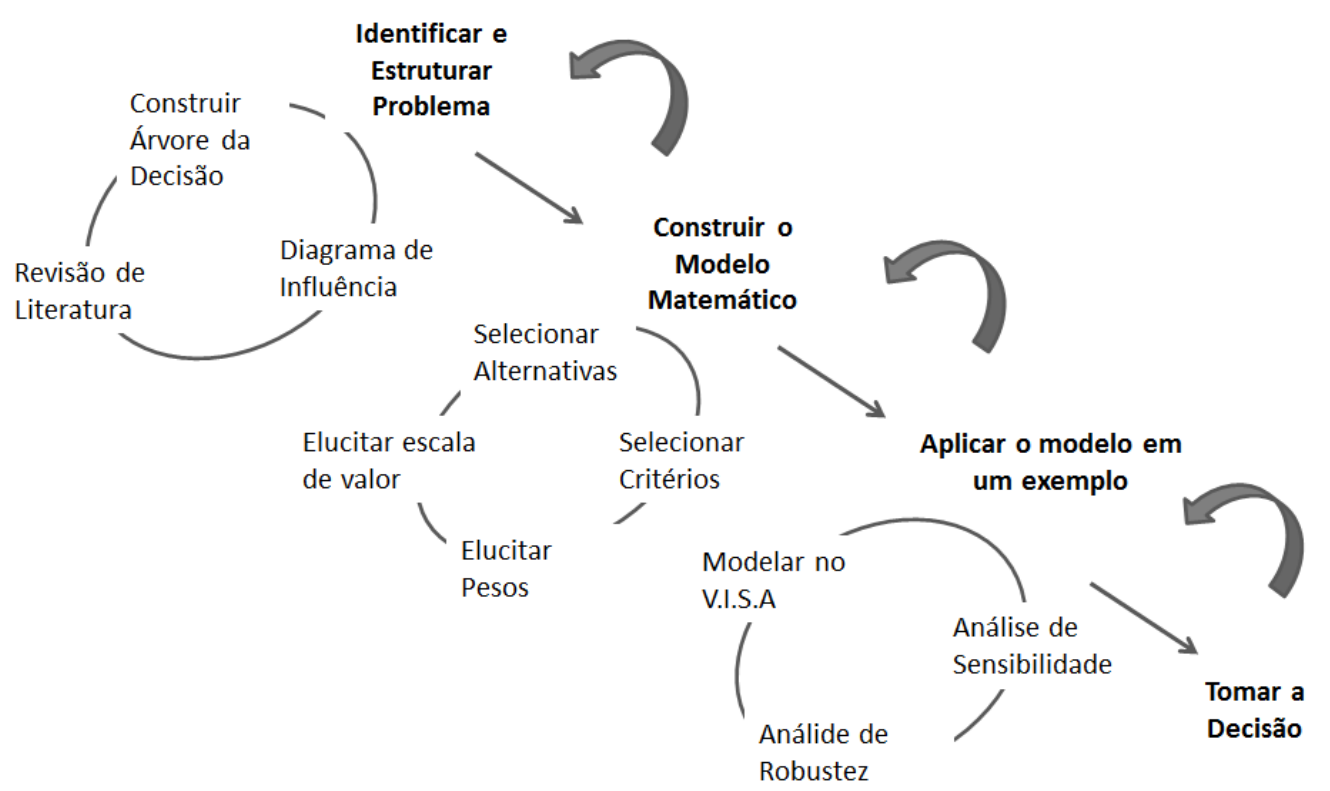

Figura 2 - Representação do processo de tomada de decisão de investir em armazenagem Fonte: Belton \& Stewart (2002)

\subsection{Escolha do método multicritério}

A Teoria da Utilidade MultiAtributo ou MultiAttribute Utility Theory (MAUT) é uma extensão clássica da teoria de utilidade que busca representar as preferências dos tomadores de decisão através de funções de utilidade para cada subcritério. Em outras palavras, o princípio é escolher a alternativa que maximize a função de utilidade proposta pelo decisor.

Por outro lado, vários métodos tratam o tema sob diferentes aspectos. Os métodos Analytic Hierarchy Process (AHP) desenvolvido por Saaty (1980) e ELECTRE (ELimination Et Choix Traduisant la REalité) estudado por Roy \& Bouyssou (1993) focam na categoria de relações de aproximações hierárquicas. O método ELECTRE exemplifica bem esta categoria, pois permite avaliar se uma alternativa a ( $a \in A$, conjunto discreto) é mais bem ranqueada que a alternativa $b(b \in A)$, mas se e somente se, tem argumento suficiente para confirmar que a é pelo menos melhor ou igual à $b$. A agregação dos critérios requer a definição de noções de preferência e indiferença e, concordância e discordância. Já os métodos baseados na desagregação de preferências utilizam de regressões para medir a preferência de um ou mais tomadores de decisão. Esta abordagem é bem parecida com o MAUT, o que os diferenciam está no procedimento de definir a função de utilidade e os pesos.

Hajkowicz et al. (2000) classificam os métodos MCDM em dois grandes grupos: contínuos e discretos, baseados na natureza das alternativas que serão avaliadas. Os métodos contínuos focam na identificação da quantidade ótima, o que pode variar infinitamente num problema de decisão. Exemplos de métodos contínuos são modelos que se baseiam em técnicas de programação linear, também conhecidos por MultiObjective Linear Programming (MOLP) e goal programming. Os métodos discretos podem ser definidos como técnicas de suporte à decisão com finitas alternativas. Estes métodos se baseiam na definição de objetivos e critérios pelas quais as alternativas serão medidas e ranqueadas, como no caso desta pesquisa. Podem ser subdivididos em métodos que mensuram o peso dos critérios ou métodos que realizem um ranking dos critérios para a seleção da alternativa. Estas categorias ainda podem ser divididas em métodos que utilizem dados quantitativos, qualitativos e/ou a combinação destes últimos (ANANDA et al, 2009).

Belton \& Stewart (2002) classificam os métodos Multi-Criteria Decision Analysis (MCDA) em três categorias: 1) Modelo de Mensuração de Valor, 2) Modelo de Programação de Meta ou Aspiração; 3) Modelo Outranking. Os modelos de Mensuração de Valor permitem que funções de valores sejam construídas para representar o valor de uma opção em relação à outra. Esta escala é determinada inicialmente para cada critério e, depois integrada. Já os métodos de Programação de 
Meta ou Aspiração são os métodos baseados em programação linear. E finalmente, os modelos Outranking baseiam em comparações paritárias das alternativas.

Comparando as classificações, a proposta por Hajkowicz et al. (2000) parece ser mais simplista já que divide em apenas dois grandes grupos baseados apenas na natureza das alternativas e não nas características da metodologia em si. As classificações de Belton \& Stewart (2002) e Pardalos (1995) classificam em mais categorias e baseiam-se no modo de medição de preferência dos critérios e alternativas pelos decisores. A diferença entre estas duas classificações está na subdivisão dos métodos baseados na Teoria de utilidade multiatributo em desagregação de preferências utilizadas por Pardalos (1995).

A análise decisão multicritério utilizada nesta pesquisa é o MAVT. Este método é adequado em casos onde mais de um critério tem características conflitantes e quando envolve problemas complexos (SALOMON, 2002) que necessariamente precisam ser subdivididos em partes menores. Estas são analisadas e ponderadas separadamente pelos decisores, com o objetivo de integrar os resultados e sugerir a decisão mais adequada para o modelo definido (GOODWIN e WRIGHT, 2004; BARFORD, 2011).

A metodologia desta pesquisa consiste no desenvolvimento de um modelo de tomada de decisão a partir da revisão de literatura e entrevistas com gestores da trading. A construção do modelo foi realizada por meio da aplicação do método de Belton \& Stewart (2002) (Figura 2).

\section{Construção do modelo multicritério}

A modelo multicritério a seguir é composto, basicamente, por três etapas: identificar e estruturar o problema, construir o modelo matemático e aplicar o modelo em um exemplo hipotético. A primeira etapa representa a fase de levantamento de informações relevantes do problema e a avaliação da sua complexidade. Logo após, é a fase de construção do modelo, onde se define os critérios, valores e alternativas que melhor representam a decisão a ser tomada. A última etapa consiste na etapa de aplicação do modelo em um exemplo hipotético a fim de analisar a viabilidade da solução proposta pelo modelo e avaliar sua consistência.

\subsection{Etapa 1 - Identificar e estruturar o problema}

A definição do problema de alocação de uma instalação de armazenagem de soja em grão se dá, principalmente, a partir de projeções futuras de aumento da safra de grãos na região, perspectivas futuras de aumento da demanda de alimento interna e mundial para os próximos anos, análise das condições atual e ao longo prazo da infraestrutura em armazenagem, transporte e capacidade portuária para o mesmo período. Ou também por decisão estratégica por parte de uma trading de aumentar a sua participação numa determinada região. Como citado, já é possível observar um déficit da produção versus infraestrutura e, seus reflexos podem ser medidos nos elevados custos logísticos que prejudicam a competitividade da soja brasileira no mercado internacional. Devido à importância dessa cadeia na economia brasileira, justifica-se a relevância da decisão de investir em armazenagem. O que falta responder é: "Em qual projeto de armazenagem investir para satisfazer os objetivos diversos do tomador de decisão na visão de uma trading?".

O problema é estruturado a partir de um diagrama de influência que consiste numa estruturação gráfica para modelar variáveis incertas (oval), decisão (retângulo), e meta (octógono) e o fluxo das informações relevantes que deverão ser considerados no processo de decisão. Segundo Cambolat et al. (2005) uma representação concisa é muito útil em entrevistas, brainstorming e desenvolvimento do consenso pelos tomadores de decisão.

Vale ressaltar que a gestão da cadeia da soja sofre influência de muitos fatores. E desta maneira, torna-se importante um aprofundamento nesses fatores nesta etapa. Os principais obtidos na literatura foram utilizados na composição do diagrama de influência, são eles: comercialização em bolsa de valores (oscilação dos preços), oferta e demanda, tributação, empresas participantes, eficiência operacional, infraestrutura logística, capacidade de armazenagem e viabilidade econômica, como mostra a Figura 3. Esses fatores serão essenciais para a composição da árvore de decisão. 


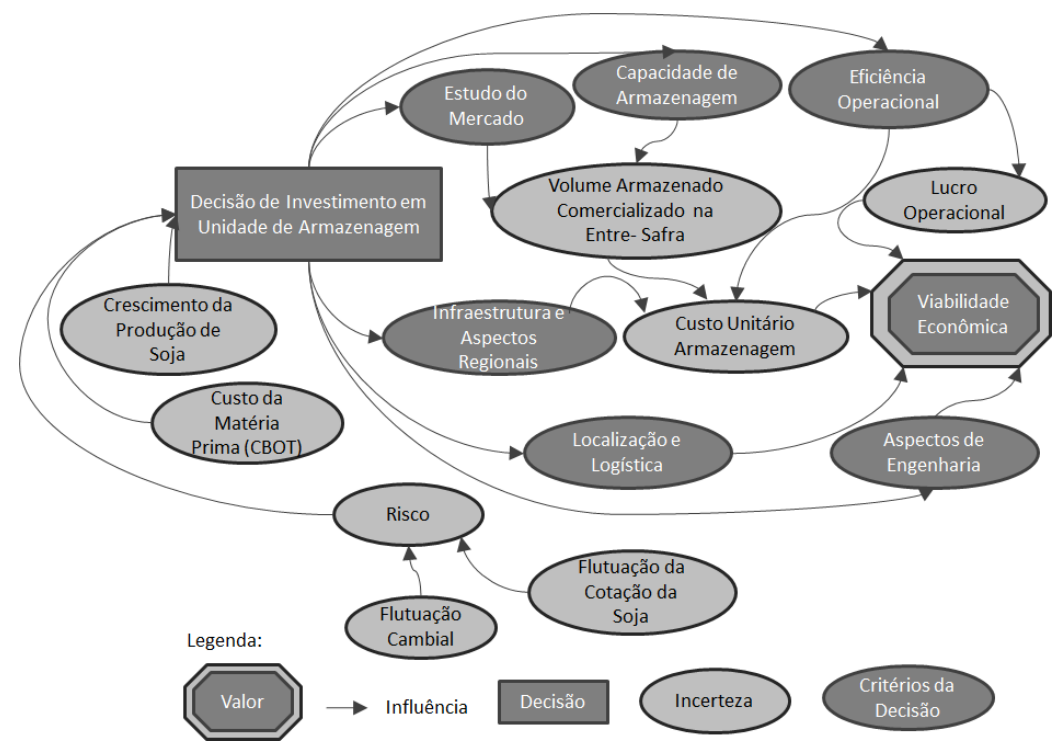

Figura 3 - Diagrama de influência da decisão de armazenagem.

A partir do diagrama de influência é possível estabelecer os objetivos fundamentais que agregarão valor à empresa em relação à decisão de escolha de armazém de soja. A representação do modelo será feita por meio de uma árvore de decisão, que será descrita na apresentação dos resultados.

\subsection{Etapa 2 - Construir o modelo matemático}

A pesquisa baseia-se nos critérios estabelecidos na vigente Instrução Normativa $n^{\circ} 29$ (MAPA, 2012), a qual consolida as normas a serem adotadas na implantação do Sistema Nacional de Certificação de Unidades Armazenadoras e, critérios e subcritérios utilizados em problemas de localização de instalações quando aplicável ao tema de armazenagem de soja a granel. O arranjo final e validação foram feitas através de entrevistas com os decisores.

Os critérios e subcritérios representados na árvore de decisão irão compor o modelo multicritério no software Visual Interactive Sensitivity Analysis (V.I.S.A.). Os critérios serão selecionados e ponderados a partir de uma adaptação da técnica de Decisão em Grupo (ou Aggregating Individual Priorities - AIP) (FORMAN; PENIWATI, 1998). O AIP agrupa de forma hierárquica as preferências individuais por meio da média geométrica das prioridades resultantes de um grupo.

A pesquisa consiste em utilizar a matriz paritária AHP (SAATY, 1980; FREITAS e CORDEIRO, 2011) para a obtenção do vetor individual de prioridade dos critérios, por meio do preenchimento de um questionário aplicado a cada tomador de decisão envolvido no processo e por meio do método AIP para obter a decisão do grupo. A agregação da comparação das alternativas sob cada subcritério também será feita no software V.I.S.A. utilizando o método a Multi-Attribute Value Theory (MAVT).

O método AIP foi escolhido já que o grupo é formado por indivíduos que não apresentam entrosamento e objetivos comuns. Cruz (2011) utilizou a abordagem AIP de decisão em grupo para obter uma avaliação global das alternativas e vetores individuais finais de prioridades. Para compor esta análise global das alternativas, de acordo com Cruz (2011), foi solicitado que cada indivíduo fizesse comparações de critérios e subcritérios entre si, e comparações das alternativas entre si sob cada subcritério e critério.

Para o alcance destes objetivos se faz necessário o levantamento das alternativas, a análise de suas consequências, a mensuração de seus impactos (KEENEY, 1992) e suas compensações (trade$o f f s$ ) para atingir mais ou menos objetivos.

Os métodos de função de valor sintetizam numericamente o desempenho das alternativas (que são medidas em relação cada critério) com a devida reflexão de importância entre os demais critérios. Porém, Belton \& Stewart (2002) ressaltam que o aprendizado e o entendimento que resultam do engajamento dos decisores em todo processo é a maior contribuição do método. 
As etapas principais do método MAVT a serem definidas são: definir os pesos dos critérios $w_{i}$ e sua normalização; determinar a escala de valor $\mathrm{v}_{\mathrm{i}}$ (a) de cada critério para mensurar o valor da alternativa; sintetizar as informações e análises de sensibilidade e robustez para validar o modelo.

Os pesos serão definidos conforme a seguinte função de valor:

$$
V(a)=\sum_{i=1}^{m} w_{i} v_{i}(a)
$$

Onde:

V(a) é o valor final da alternativa a;

$\mathrm{v}_{\mathrm{i}}(\mathrm{a})$ é o valor que reflete o desempenho da alternativa a em relação ao critério i;

$w_{\mathrm{i}}$ é o peso que reflete a importância do critério i.

Num processo de tomada de decisão observa-se que geralmente os critérios não possuem o mesmo peso. Sendo assim, é importante criar uma relação de importância entre os critérios para ponderar os pesos da maneira que melhor reflita a preferência dos tomadores de decisão.

Como sugerido por Keeney (1996), o foco no processo de tomada de decisão será o "Pensamento em Valor", ou seja, o método seguirá a sequência: definição de objetivos a serem atingidos por meio da determinação dos subcritérios que medirão o quão os objetivos serão atendidos. A seleção das alternativas serão os meios para que os objetivos sejam alcançados. $\mathrm{O}$ autor explica que para basear-se em "Valor" é necessário torná-lo explícito a partir de um profundo estudo dos objetivos a serem buscados, para depois criar as alternativas que servirão para agregar tais valores.

A determinação de valor, ou em inglês 'Scoring' é o processo de medir o desempenho da alternativa em relação a um critério ou subcritério, ou seja, significa medir a função de valor parcial $\mathrm{v}_{\mathrm{i}}$ (a) do modelo (Equação 1). Como os critérios serão construídos na forma de uma árvore de decisão, as alternativas devem ser medidas em relação a todos os níveis da árvore.

Nesta pesquisa, a escala de valor para avaliar as alternativas será do tipo local, ou seja, a alternativa que apresentar o melhor desempenho em um determinado critério é o que assumirá o valor 100 da escala e o pior desempenho será posicionado no ponto 0. Os critérios qualitativos serão avaliados por escala de valor de três níveis onde o valor 100 é o alto, 50 é o médio e 0 o valor baixo. Os critérios quantitativos poderão ser lineares, quando a escala de valor seja representado por uma equação linear, se comportando como uma reta. Neste caso, assume-se que uma mudança de igual magnitude no critério tem o mesmo valor em qualquer segmento do intervalo definido. Ou não linear, quando a escala de valor for qualquer outra curva, ou seja, uma mudança da mesma magnitude no nível dos critérios nem sempre tem o mesmo valor ou não sempre influi da mesma maneira na decisão. A definição será feita pelo analista, o que pode ser considerado como uma limitação desta pesquisa por não ter as preferências dos decisores nesta etapa.

\subsection{Etapa 3 - Aplicar o modelo em um exemplo hipotético - uso do software V.I.S.A.}

O V.I.S.A. é um programa computacional de apoio à decisão desenvolvido pela SIMUL8 (www.simul8.com/visa). Este software auxilia na construção de problemas de escolha discreta ao aplicar medidas de valor a múltiplos subcritérios, onde as decisões são modeladas usando uma hierarquia de funções (critérios) ponderada entre si. Para avaliar a coerência dos critérios e assertividade dos resultados da análise multicritério serão realizadas análises de robustez e de sensibilidade.

Uma importante característica deste software está em sua interface baseada na interação visual, o que permitiu a exploração em tempo real e a verificação das implicações das trocas de diferentes prioridades (tentativa e erro), valores e pesos dos subcritérios e critérios durante sua análise de robustez e sensibilidade. Este fato possibilitou verificar as quais necessitariam ser os pesos dos critérios pelos decisores, para que cada uma das três alternativas (projetos) fossem eleitas. 


\section{Apresentação e Análise dos Resultados}

\subsection{Etapa 1 - - Identificação e estruturação do problema - Árvore de decisão}

O problema foi estruturado na seção 3.1 por meio do diagrama de influências. Com base na literatura e nos subcritérios valorados por gestores da Trading foi possível montar a árvore de decisão que constitui um modelo de apoio à escolha de projetos de armazenagem para soja em grão, como mostra a Figura 4.

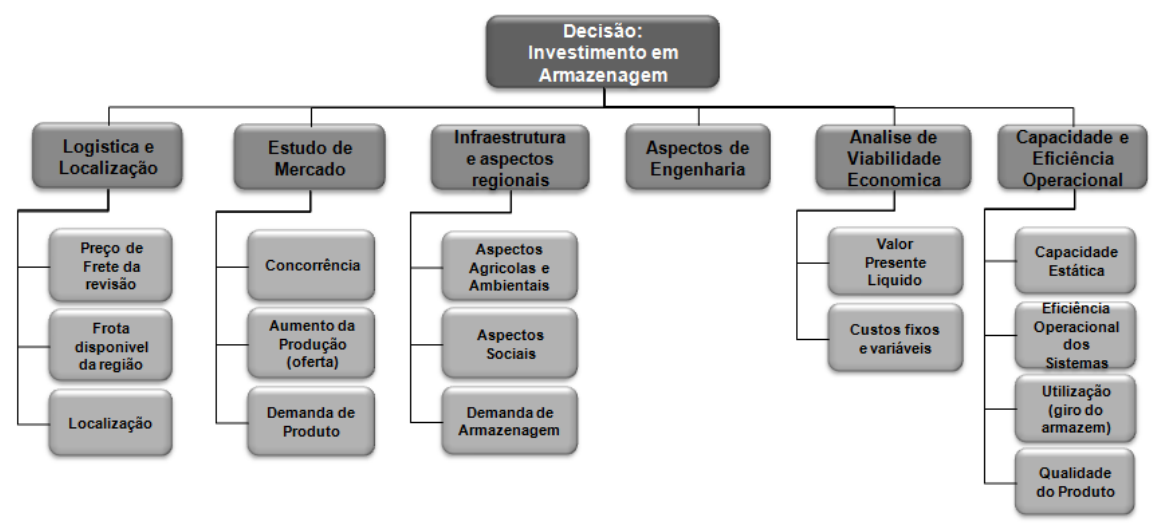

Figura 4 - Árvore de decisão para escolha de armazém de soja

Fonte: Dados da pesquisa

\subsection{Etapa 2 - - Construção do modelo matemático para a árvore de decisão}

\subsubsection{Definição dos pesos de critérios e subcritérios}

A ponderação dos critérios e subcritérios da decisão em grupo contou com a participação de profissionais que atuam em uma trading do setor do agronegócio. Hora, Monteiro e Arica também fundamentaram a confiabilidade de dados com base na ponderação de critérios pela consulta a especialistas. O perfil destes profissionais foi composto por analista, coordenador, gerente e diretor das áreas de suprimentos (compra de matéria prima), armazenagem, logística e planejamento. O grupo foi composto por profissionais que trabalham nas áreas que se relaciona direta ou indiretamente com uma unidade armazenadora de uma trading do setor agrícola. Os resultados da média geométrica (método AIP) critério a critério da decisão em grupo e a hierarquia dos critérios (método AHP) calculada a partir dos dados obtidos dos questionários se encontram na Tabela 1.

Tabela 1 - Média geométrica da decisão do grupo e a importância dos critérios

\begin{tabular}{|c|c|c|c|c|c|c|c|}
\hline CRITÉRIO & $\begin{array}{l}\text { Localização e } \\
\text { Logistica }\end{array}$ & $\begin{array}{l}\text { "Estudo de } \\
\text { Mercado" }\end{array}$ & $\begin{array}{c}\text { Infraestrutura e } \\
\text { aspectos agricolas } \\
\text { regionais }\end{array}$ & $\begin{array}{l}\text { Aspectos de } \\
\text { Engenharia }\end{array}$ & $\begin{array}{l}\text { Análise de } \\
\text { Viabilidade } \\
\text { Econômica }\end{array}$ & $\begin{array}{l}\text { Capacidade e } \\
\text { Eficiência } \\
\text { Operacional }\end{array}$ & $\begin{array}{c}\text { Prioridade } \\
\text { Relativa }\end{array}$ \\
\hline "Localização e Logistica" & 1,0 & 1,6 & 1,5 & 4,6 & 0,6 & 1,4 & 0,216 \\
\hline "Estudo de Mercado" & 0,6 & 1,0 & 2,1 & 3,8 & 1,0 & 1,6 & 0,206 \\
\hline $\begin{array}{l}\text { Infraestrutura e aspectos } \\
\text { agricolas regionais }\end{array}$ & 0,7 & 0,5 & 1,0 & 4,4 & 0,9 & 1,7 & 0,172 \\
\hline Aspectos de Engenharia & 0,2 & 0,3 & 0,2 & 1,0 & 0,4 & 0,7 & 0,061 \\
\hline $\begin{array}{l}\text { Análise de Viabilidade } \\
\text { Econômica }\end{array}$ & 1,8 & 1,0 & 1,1 & 2,7 & 1,0 & 2,2 & 0,232 \\
\hline $\begin{array}{c}\text { Capacidade e Eficiência } \\
\text { Operacional }\end{array}$ & 0,7 & 0,6 & 0,6 & 1,5 & 0,4 & 1,0 & 0,113 \\
\hline
\end{tabular}

De acordo com a Figura 5, o resultado da preferência do grupo pelo critério "Analise de Viabilidade Econômica" mostra a elevada relevância desta avaliação na decisão. É o critério que se 
encontra no topo da distribuição hierarquia com o peso relativo de 0,232. Os resultados dos questionários mostraram que para avaliar este critério, grupo considera "VPL" mais importante que o subcritério "qualificação dos custos fixos e variáveis".

O segundo critério na hierarquia de importância foi "Localização e Transporte" com o peso relativo de 0,216. Ou seja, numa decisão de armazenagem de soja em grão o grupo considerou relevante à localização e as condições de transporte que compõe a região dos projetos estudados. Para avaliar este critério, foram selecionados, segundo as preferências dos profissionais, quatro subcritérios, são eles: "localização", "preço de frete na região", "frota disponível" e "modais de recepção e expedição". Os resultados dos questionários mostraram que para avaliar o critério "Localização e Transporte" os subcritérios mais importantes são "preço de frete da região" e "localização".

Logo após, o critério "Estudo de mercado" aparece em terceiro lugar na hierarquia de importância com o peso relativo de 0,206. Para avaliar este critério foram selecionados três subcritérios, são eles: "concorrência", "aumento da produção" e "demanda de produto". Os resultados dos questionários mostraram que para avaliar o critério "Estudo do mercado" os subcritérios mais importantes são "concorrência" e "demanda de produto".

O critério "Infraestrutura e aspectos regionais" vem a seguir com o peso relativo 0,172 na hierarquia de importância. Este critério é avaliado pelos subcritérios: "aspectos sociais", "demanda de armazenagem" e "aspectos agrícolas e ambientais" sendo estes dois últimos considerados mais importantes na opinião do grupo.

Em penúltimo lugar na preferência do grupo coloca o critério "Capacidade e Eficiência Operacional" com o peso relativo de 0,113. Os subcritérios selecionados para medi-lo foram: "capacidade estática", "utilização (giros de armazém)", "eficiência dos sistemas e linhas de processamento" e "qualidade do produto". Os resultados dos questionários mostraram que para avaliar este critério, os subcritérios mais importantes são "eficiência dos sistemas e linhas de processamento" e "utilização (giros de armazém)".

E finalmente, o critério "Aspectos de engenharia" aparece em último lugar na hierarquia de importância com o peso relativo de 0,061 . O critério "Aspectos de engenharia" não tem subcritério vinculado.

Logo, sugere-se que os critérios relacionados à logística são os mais relevantes, além da análise de viabilidade econômica. Este resultado, de certa forma, corrobora a literatura na medida em que evidencia a importância de melhorias de infraestrutura logística para escoamento e armazenagem dos grãos.

\subsubsection{Hierarquia global dos subcritérios}

A hierarquia global dos subcritérios distribui as respectivas posições levando em consideração todos os subcritérios da árvore de decisão e não somente do critério que os abrangem (Tabela 2). Na coluna de "maior valor"e "menor valor" foram inseridos os maiores e menores valores de preferência em relação a cada subcritério resultantes dos questionários dos 11 decisores e, "decisão do grupo" corresponde ao resultado de preferência do subcritério em questão da decisão do grupo. 
Tabela 2 - Resultados global da preferência dos decisores

\begin{tabular}{|c|c|c|c|c|c|}
\hline Critérios & Subcritérios & $\begin{array}{l}\text { Maior } \\
\text { Valor }\end{array}$ & $\begin{array}{l}\text { Decisão do } \\
\text { Grupo }\end{array}$ & Menor Valor & $\begin{array}{l}\text { Hierarquia da } \\
\text { Decisão em } \\
\text { Grupo }\end{array}$ \\
\hline \multirow{4}{*}{ 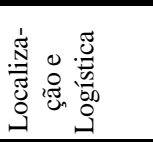 } & Localização & 0,194 & 0,66 & 0,005 & $6^{\circ}$ \\
\hline & Preço de Frete da Região & 0,190 & 0,075 & 0,015 & $5^{\circ}$ \\
\hline & Frota disponível na Região & 0,065 & 0,048 & 0,024 & $10^{\circ}$ \\
\hline & Modais de Recepção e Expedição & 0,093 & 0,028 & 0,009 & $15^{\circ}$ \\
\hline \multirow{3}{*}{ 号 } & Concorrência (aumento de Market Share) & 0,169 & 0,080 & 0,021 & $3^{\circ}$ \\
\hline & Aumento da Produção (Oferta) & 0,124 & 0,047 & 0,006 & $11^{\circ}$ \\
\hline & Demanda de Produto & 0,139 & 0,078 & 0,012 & $4^{\circ}$ \\
\hline \multirow{3}{*}{ 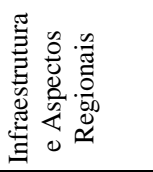 } & Aspectos Agrícolas e Ambientais & 0,110 & 0,061 & 0,010 & $7^{\circ}$ \\
\hline & Demanda de Armazenagem & 0,167 & 0,081 & 0,020 & $2^{\circ}$ \\
\hline & Aspectos Sociais & 0,077 & 0,030 & 0,008 & $14^{\circ}$ \\
\hline 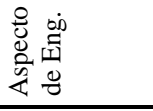 & Aspecto de Engenharia & 0,164 & 0,061 & 0,022 & $8^{\circ}$ \\
\hline \multirow{2}{*}{ 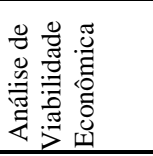 } & Valor Presente Líquido & 0,289 & 0,172 & 0,040 & $1^{\circ}$ \\
\hline & $\begin{array}{c}\text { Qualificação e Quantificação dos Custos } \\
\text { Fixos e Variáveis }\end{array}$ & 0,249 & 0,060 & 0,007 & $9^{\circ}$ \\
\hline \multirow{4}{*}{ 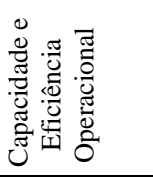 } & Capacidade Estática & 0,083 & 0,028 & 0,008 & $16^{\circ}$ \\
\hline & $\begin{array}{l}\text { Eficiência dos sistemas e linhas de } \\
\text { processamento }\end{array}$ & 0,254 & 0,034 & 0,001 & $12^{\circ}$ \\
\hline & Utilização (Giros de Armazém) & 0,100 & 0,030 & 0,006 & $13^{\circ}$ \\
\hline & Qualidade do Produto & 0,095 & 0,021 & 0,004 & $17^{\circ}$ \\
\hline
\end{tabular}

A Tabela 2 mostra que os cinco subcritérios mais importantes da decisão de investir em uma unidade de armazenagem em grão são: "VPL", "demanda de armazenagem", "concorrência"; "demanda de produto" e "preço de frete da região". Observa-se que estes cinco subcritérios pertencem aos critérios: "Análise de Viabilidade Econômica", "Infraestrutura e Aspectos Regionais", "Estudo de Mercado" e "Localização e Transporte". Esse resultado sugere os subcritérios mais relevantes se referem à perspectiva de aumento de mercado e preocupação com a diminuição de custos logísticos, classificados por Biagi et al. (2002; pp. 157-160) como aspectos extrínsecos, relacionados ao transporte e comercialização. Observa-se também que os subcritérios "Qualidade" e "Capacidade estática" foram os menos relevantes. Talvez isto possa revelar "critérios qualitativos" que as empresas deveriam ter para se manter no mercado. No entanto, a partir destas informações de relevância dos subcritérios e critérios, novas pesquisas podem ser propostas para aferir essas questões, inclusive com participação de profissionais que atuam em outras regiões do país.

\subsubsection{Selecionar as Alternativas}

O processo de decisão desta pesquisa envolve três alternativas de projetos hipotéticos de unidade de armazenagem com os seguintes perfis (vide Tabela 3):

- Projeto A é composto de um silo metálico com plenamente dos requisitos (obrigatório e recomendado) atendidos segundo a Instrução Normativa $\mathrm{N}^{\circ} 29$ e capacidade de 30.000 toneladas. Quanto à localidade, fica situado numa área rural próxima às fazendas e com grande potencial de aumento participação do mercado (Market Share). Como a capacidade do armazém é relativamente baixa, necessitará de muitos giros de armazém para garantir diminuição de custos e VPL maior que zero, desta maneira sua atratividade econômica é baixa;

- Projeto B é composto de um armazém graneleiro com plenamente dos requisitos obrigatórios atendidos segundo a Instrução Normativa $\mathrm{N}^{\circ} 29$ e capacidade de 100.000 toneladas. Quanto à localidade, fica situado numa área rural mais afastado das fazendas com médio potencial de aumento de participação do mercado (Market Share), já que o mesmo já se encontra mais consolidado. Devido a sua elevada capacidade do armazém sua atratividade econômica é alta, uma vez que consegue diluir melhor seus custos fixos; 
- Projeto C é composto de um armazém graneleiro com plenamente dos requisitos obrigatórios atendidos segundo a Instrução Normativa $\mathrm{N}^{\circ} 29$ e capacidade de 50.000 toneladas. Quanto à localidade, fica situado numa área urbana com baixo potencial de aumento na participação do mercado (Market Share). Devido a sua média capacidade do armazém sua atratividade econômica é média, já que dependerá de giros de armazém para garantir o volume necessário para balancear seus custos.

Tabela 3- Valoração dos subcritérios

\begin{tabular}{|c|c|c|c|c|c|c|c|}
\hline Critérios & Subcritérios & $\begin{array}{l}\text { Unidade de } \\
\text { medida }\end{array}$ & Projeto A & Projeto B & Projeto C & $\begin{array}{l}\text { Escala de } \\
\text { Valor }\end{array}$ & Preferência \\
\hline \multirow{4}{*}{ 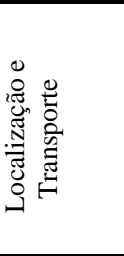 } & Localização & $\mathrm{Km}$ & 100 & 200 & 300 & 100 a 300 & menor valor \\
\hline & $\begin{array}{l}\text { Preço de Frete da } \\
\text { Região }\end{array}$ & $\mathrm{R} \$ / \mathrm{km}$ & 5,70 & 5,40 & 4,60 & 4,60 a 5,70 & menor valor \\
\hline & $\begin{array}{c}\text { Frota disponível na } \\
\text { Região }\end{array}$ & Qualitativa & baixo & médio & Alto & baixo a alto & alto melhor \\
\hline & $\begin{array}{l}\text { Modais de Recepção } \\
\text { e Expedição }\end{array}$ & Qualitativo & baixo & médio & Alto & baixo a alto & alto melhor \\
\hline \multirow{3}{*}{ 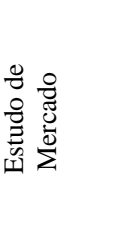 } & $\begin{array}{l}\text { Concorrência } \\
\text { (aumento } \\
\text { market share) }\end{array}$ & Qualitativo & alto & médio & Baixo & baixo a alto & alto melhor \\
\hline & $\begin{array}{c}\text { Aumento da } \\
\text { Produção (Oferta) }\end{array}$ & $\%$ & 15 & 5 & 10 & 5 a 15 & maior valor \\
\hline & $\begin{array}{l}\text { Demanda de } \\
\text { Produto }\end{array}$ & $\%$ & 15 & 5 & 10 & 5 a 15 & maior valor \\
\hline \multirow{4}{*}{ 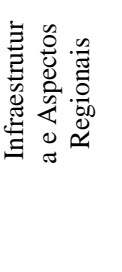 } & $\begin{array}{l}\text { Aspectos Agrícolas } \\
\text { e Ambientais }\end{array}$ & Qualitativo & alto & baixo & Alto & baixo a alto & alto melhor \\
\hline & $\begin{array}{c}\text { Demanda de } \\
\text { Armazenagem }\end{array}$ & $\%$ & 20 & 15 & 15 & 15 á 20 & maior valor \\
\hline & Aspectos Sociais & Qualitativo & baixo & médio & Alto & baixo a alto & alto melhor \\
\hline & $\begin{array}{l}\text { Aspecto de } \\
\text { Engenharia }\end{array}$ & Qualitativo & alto & médio & médio & $\begin{array}{l}\text { médio a } \\
\text { alto }\end{array}$ & alto melhor \\
\hline \multirow[b]{2}{*}{ 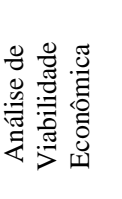 } & $\begin{array}{l}\text { Valor Presente } \\
\text { Líquido }\end{array}$ & Qualitativo & baixo & alto & Médio & baixo a alto & alto melhor \\
\hline & $\begin{array}{c}\text { Qualificação e } \\
\text { Quantificação dos } \\
\text { Custos Fixos e } \\
\text { Variáveis } \\
\end{array}$ & $\mathrm{R} \$ /$ ton. & 20 & 18 & 19 & 18 a 20 & menor valor \\
\hline \multirow{4}{*}{ 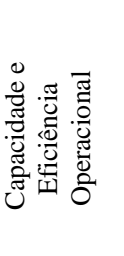 } & $\begin{array}{l}\text { Capacidade Estática } \\
\text { Eficiência dos }\end{array}$ & kton. & 30 & 100 & 50 & 30 a 100 & maior valor \\
\hline & $\begin{array}{l}\text { sistemas e linhas de } \\
\text { processamento }\end{array}$ & Qualitativo & baixo & alto & Médio & baixo a alto & alto melhor \\
\hline & $\begin{array}{l}\text { Utilização (Giros de } \\
\text { Armazém) }\end{array}$ & giros & 3 & 1 & 2 & 1 a 3 & maior valor \\
\hline & $\begin{array}{c}\text { Qualidade do } \\
\text { Produto } \\
\end{array}$ & qualitativo & Alto & baixo & Médio & baixo a alto & alto melhor \\
\hline
\end{tabular}

\subsection{Etapa 3 - Aplicação do modelo em um caso hipotético- uso do software V.I.S.A.}

Após a determinação dos pesos dos critérios e subcritérios, das escalas de valores de cada subcritério e dos valores das alternativas, como apresentados anteriormente, estas informações foram inseridas no software V.I.S.A. para sua modelagem matemática. Os resultados podem ser vistos na Figura 5. 

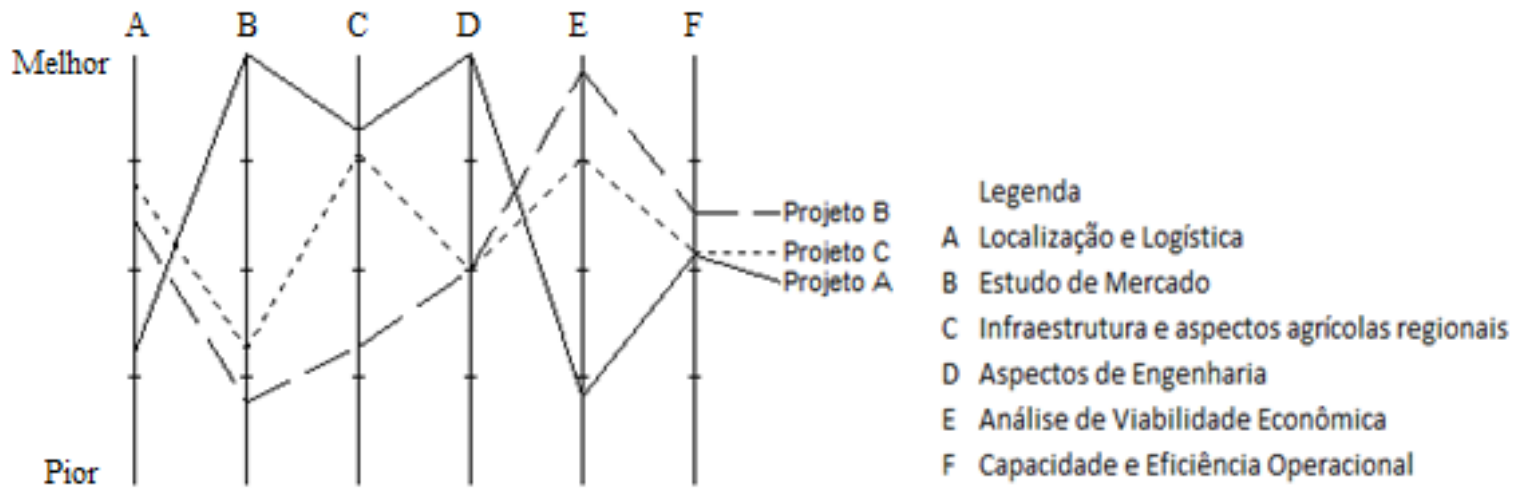

Figura 5 - Valoração dos projetos segundo os critérios da árvore de decisão

O projeto A obteve maior pontuação local nos critérios "Estudo de Mercado", "Infraestrutura e Aspectos Regionais" e "Aspectos de Engenharia", o que significa que o Projeto A melhor atende as exigências destes três objetivos quando comparado com os outros três projetos. Isto se deve, principalmente, à região onde o projeto será instalado apresentar o maior potencial de crescimento de produção de soja e de demanda pelos serviços de armazenagem, características essenciais de mercado. Em contrapartida, nos critérios "Localização e Transporte", "Análise de Viabilidade Econômica" e "Capacidade e Eficiência Operacional", o projeto A apresentou as menores pontuações, o que significa que os outros dois projetos atendem melhor às expectativas dos decisores sob estes três aspectos.

O projeto B apresentou maiores pontuações nos critérios "Análise de Viabilidade Econômica" e "Capacidade e Eficiência Operacional", fato este alavancado pela maior capacidade estática do armazém (100 kt) dentre os três projetos, o que pode ser considerado o ponto forte deste projeto. Porém a região onde o projeto será inserido não atende plenamente as necessidades dos decisores quanto às demandas do "Estudo de Mercado" e exigências de "Infraestrutura e Aspectos Regionais", nos quais obtiveram menores pontuações.

E, por fim, o projeto C foi melhor pontuado quanto a sua "Localização e Transporte". Apesar de ser o projeto mais distante das principais áreas produtoras, a região apresenta melhor sistema de transporte e maior disponibilidade de frota com fretes mais baratos dentre os outros projetos. Em relação ao critério "Aspectos de Engenharia", apesar de atender aos requisitos mínimos da Instrução Normativa 29 para obter a certificação da unidade armazenadora, os outros dois projetos apresentam mais requisitos não obrigatórios atendidos, o que ocasionou na menor pontuação do projeto $\mathrm{C}$, neste quesito. $\mathrm{O}$ projeto $\mathrm{C}$ ficou em segundo lugar nos outros quatro critérios.

Como se trata de uma decisão multicritério, o resultado final é a seleção do projeto que obtém a maior pontuação geral do somatório dos valores de cada projeto (alternativa) ponderados pelos pesos de cada critério. Ou seja, o modelo elege o projeto que melhor atender a maioria dos objetivos exigidos na decisão. Sendo assim, o modelo de decisão de armazém de soja em grão proposto por este trabalho, sob a visão do grupo, foi o projeto $\mathrm{C}$.

De acordo com o perfil do projeto A, as condições que fariam com que o modelo indicasse esta alternativa como a mais indicada teria que apresentar a sequência de pesos para os critérios como mostra a Figura 6, sendo "Estudo de mercado", o critério com maior valor, impulsionado pelo aumento do peso dos subcritérios "Concorrência" e "Demanda de produto". Isso daria vantagem ao projeto A em relação aos projetos B e C por permitir o maior potencial de aumento Market Share da empresa na região deste projeto. 


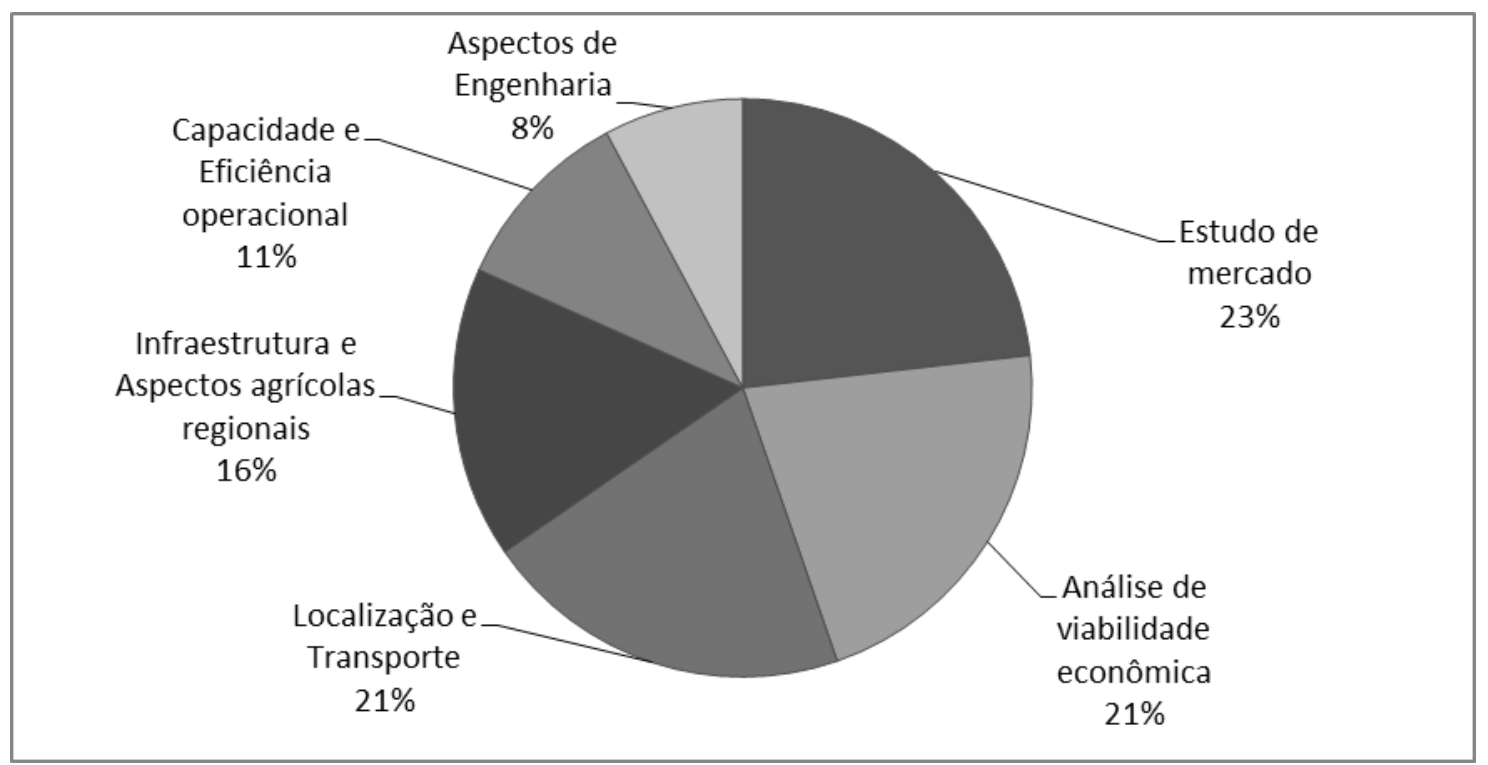

Figura 6 - Resultados da análise de sensibilidade para eleição do projeto $\mathrm{A}$

Agora de acordo com o perfil do projeto $\mathrm{B}$, as condições que fariam com que o modelo indicasse esta alternativa como a mais indicada teria que apresentar a sequência de pesos para os critérios como mostra a Figura 7, sendo "Capacidade e Eficiência operacional", o critério com maior valor, impulsionado pelo aumento do peso dos subcritérios "Capacidade estática e Eficiência dos sistemas operacionais". Isso daria vantagem ao projeto B em relação aos projetos A e C por permitir o maior potencial em garantir o alcance do objetivo do armazenamento que é guardar e preservar as características que os grãos apresentam após a colheita, diminuindo ao máximo as perdas, utilizandose, da melhor maneira possível, a capacidade e as técnicas existentes.

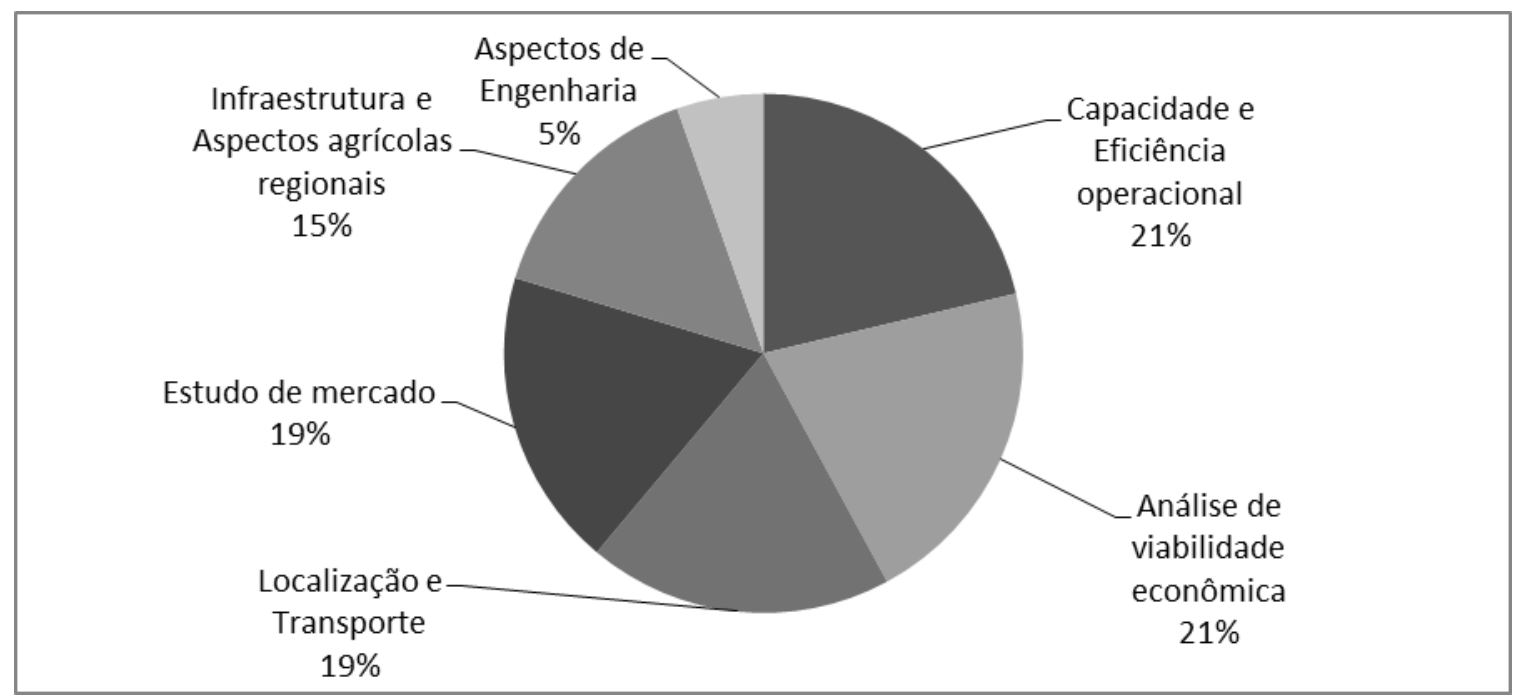

Figura 7 - Resultados da análise de sensibilidade para eleição do projeto B

Comparando os resultados da decisão do grupo com os resultados da análise de sensibilidade como mostra a Figura 8, observa-se que os critérios mais sensíveis são os que apresentam o menor desvio entre os resultados das análises de sensibilidade e a decisão do modelo proposto, são eles "Infraestrutura e Aspectos agrícolas da região" e "Análise de viabilidade econômica". Enquanto o critério "capacidade e eficiência operacional" é o menos sensível à mudança (com maior desvio), o que confere robustez ao modelo. Ou seja, a conservação da qualidade e controle de perdas parecem ser características fundamentais na escolha de projetos em armazenagem, seja pelo ponto de vista do eficiente controle de estoque e adequada capacidade estática de armazenagem, seja pela eficiência dos sistemas e linhas de processamento e qualidade do grão. 


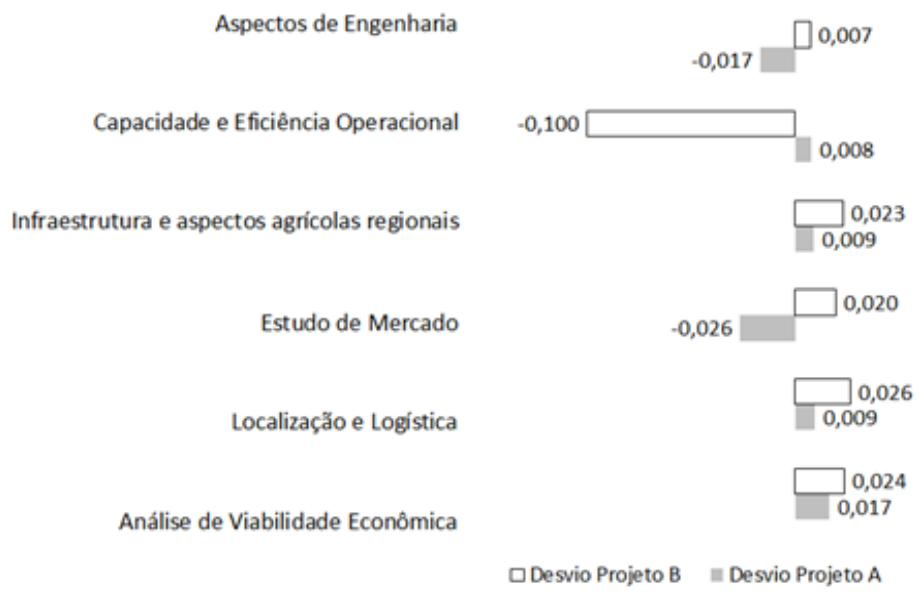

Figura 8 - Análise de sensibilidade dos critérios quanto à mudança nos pesos

O critério "Localização e Transporte", embora apresente pouca sensibilidade a mudanças nos projetos hipotéticos, certamente o aumento ou diminuição do seu peso influencia substancialmente a escolha do projeto, uma vez que a localização entre o armazém e os pontos de origem (fazenda) e destino (mercado consumidor), o preço de frete e a frota disponível na região poderão alterar a necessidade de aumentar ou diminuir a capacidade estática e aumentar o giro do armazém. Analogamente, dependendo da região, "Infraestrutura e aspectos agrícolas regionais" também poderão influenciar na escolha do armazém, pois fluxos frequentes de carga, períodos de safra e entressafra, além de custos locais de armazenagem serão relevantes à medida que revela as necessidades de atendimento de diversas demandas (sociais, ambientais e espaço físico para armazenagem).

\section{Conclusões}

A principal contribuição desta pesquisa foi construir um modelo de decisão multicritério de armazenagem de soja em grão com base na literatura e na escala de importância dos critérios de acordo com as preferências de profissionais que trabalham no setor. Apesar de ser uma aplicação hipotética e não estudo de caso real, o modelo proposto demonstrou-se coerente em relação ao perfil das alternativas criadas e validadas pela análise de sensibilidade.

A pesquisa revelou quais são os critérios de maior relevância, além da análise econômica, para a escolha de centros hipotéticos (projetos) de armazenagem, segundo as preferências de um grupo de decisores. Certamente, os critérios "Localização e Logística de Transporte", "Infraestrutura e Aspectos agrícolas regionais" e "Capacidade e Eficiência operacional", embora sejam independentes entre si sob o ponto de vista da modelagem das preferências do grupo, se referem exclusivamente aos aspectos logísticos. Logo, a análise conjunta desses critérios demandam mais pesquisas, pois parecem ter destaque na decisão de investimento em armazenagem e, como exposto, são o gargalo frente ao cenário futuro de aumento da safra e de consumo.

O publico alvo desta pesquisa foram gerentes, diretores e tomadores de decisão que desejam escolher projetos de investimento em unidades armazenadoras de soja. Esta pesquisa pode ser utilizada como parte do processo de tomada de decisão em situações reais. Outra relevante contribuição é a agregação de opiniões individuais para se obter uma valoração quantitativa da decisão de um grupo. Fato este que aproxima da realidade os processos de tomada de decisão em empresas. Pois, geralmente mais de uma pessoa de diversas áreas estão envolvidas numa decisão de investimento em projeto de armazenagem. No entanto, a falta de validação dos critérios e subcritérios por meio de um caso real se configura a limitação desta pesquisa.

Uma recomendação para compor futuras pesquisas sobre o assunto encontra-se na consideração de uma análise de incerteza, a partir da construção de uma árvore de probabilidade para as alternativas propostas no modelo. Estas alternativas podem ser baseadas na previsão de realização da produtividade da safra e dados históricos para a definição das condições de sucesso e fracasso. Além disso, análise de cenários e/ou elaboração de mais critérios que levem alguma análise de incerteza em sua construção para minimizar o risco da decisão, podem ser acrescentadas à pesquisa. 
Apêndice A - Questionário de pesquisa.

\section{Universidade de São Paulo}

\section{DADOS GERAIS}

\begin{tabular}{|l|l}
\hline Nome: & Local: \\
\hline Cargo e Área: & Data: \\
\hline \multicolumn{2}{|c|}{ AVALIAÇÃO DE CRIIÉRIOS EM UM PROCESSO DE DECISÃO DE INVESTIMENTO EM ARMAZENAGEM DE SOJA } \\
\hline
\end{tabular}
Buscando obter o maior valor no processo de tomada de uma decisão de investimento em Armazenagem de Soja em grão, gostaria de saber quais critérios e qual importância entre eles que você

Você deverá atribuir para cada item uma nota de $1 / 9$ à 9 , segundo escala ao lado, onde 1/9 significa que o primeiro critério é nove vezes menos importante ou "Pobreamente Pior" em relação ao segundo critério e 9 significa que o primeiro critério é nove vezes mais importante ou "Absolutamente Melhor" em relação ao segundo critério.

Ao completar este formulário de avaliação, você colabora com a minha pesquisa de mestrado pela Universidade de São Paulo

Para comparar o que você considera importante entre os dois critérios:

\begin{tabular}{|cll|l|l}
\hline 01. & "Localização e Logistica" & em relação & "Estudo de Mercado" & Absolutamente melhor \\
\hline 02. & "Localização e Logistica" & em relação & "Infraestrutura e aspectos regionais" & \\
\hline 03. & "Localização e Logistica" & em relação & "Aspectos de Engenharia" & \\
\hline 04. & "Localização e Logistica" & em relação & "Análise de Viabilidade Econômica" & \\
\hline 05. & "Localização e Logistica" & em relação & "Capacidade e Eficiência Operacional" & \\
\hline 06. & "Estudo de Mercado" & em relação & "Infraestrutura e aspectos regionais" & \\
\hline 07. & "Estudo de Mercado" & em relação & "Aspectos de Engenharia" & \\
\hline 08. & "Estudo de Mercado" & em relação & "Análise de Viabilidade Econômica" & \\
\hline 09. & "Estudo de Mercado" & em relação & "Capacidade e Eficiência Operacional" & \\
\hline 10. & "Infraestrutura e aspectos regionais" & em relação & "Aspectos de Engenharia" & \\
\hline 11. & "Infraestrutura e aspectos regionais" & em relação & "Análise de Viabilidade Econômica" & \\
\hline 12. & "Infraestrutura e aspectos regionais" & em relação & "Capacidade e Eficiência Operacional" & \\
\hline 13. & "Aspectos de Engenharia" & em relação & "Análise de Viabilidade Econômica" & \\
\hline 14. & "Aspectos de Engenharia" & em relação & "Capacidade e Eficiência Operacional" \\
\hline 15. & "Análise de Viabilidade Econômica" & em relação & "Capacidade e Eficiência Operacional" \\
\hline 16. & Outro critério que considera relevante: & & \\
\hline
\end{tabular}

Para comparar o que você considera importante entre os dois atributos em relação ao critério "Localização e Logística":

\begin{tabular}{|c|c|c|c|c|}
\hline 01. & "Localização" & em relação & "Preço de frete da região" & Criticamente melhor \\
\hline 02. & "Localização" & em relação & "Frota disponivel na região" & \\
\hline 03. & "Localização" & em relação & "Modais de recepção e expedição" & \\
\hline 04. & "Preço de frete da região" & em relação & "Frota disponivel na região" & \\
\hline 05. & "Preço de frete da região" & em relação & "Modais de recepção e expedição" & \\
\hline 06. & "Frota disponivel na região" & em relação & "Modais de recepção e expedição" & \\
\hline 07. & Outro atributo que consider & ara o critéric & calização e Logistica": & \\
\hline
\end{tabular}

Para comparar o que você considera importante entre os dois atributos em relação ao critério "Estudo de Mercado":

\begin{tabular}{|clc|c|}
\hline 01. & "Concorrência" & em relação $\quad$ "Aumento de Produção (Oferta)" & Criticamente melhor \\
\hline 02. & "Concorrência" & em relação $\quad$ "Demanda de Produto" & \\
\hline 03. & "Demanda de Produto" & em relação $\quad$ "Aumento de Produção (Oferta)" & \\
\hline 04. & Outro atributo que considera relevante para o critério "Estudo de Mercado": & \\
\hline
\end{tabular}

Para comparar o que você considera importante entre os dois atributos em relação ao critério "Infraestrutura e Aspectos Regionais":

\begin{tabular}{|clcc|c|}
\hline 01. & "Aspectos agricolas e Ambientais" & em relação $\quad$ "Demanda de Armazenagem da Região " & Criticamente melhor \\
\hline 02. & "Aspectos agricolas e Ambientais" & em relação $\quad$ "Aspectos Sociais" & \\
\hline 03. & "Aspectos Sociais" & em relação $\quad$ "Demanda de Armazenagem da Região " & \\
\hline 04. & Outro atributo que considera relevante para o critério "Infraestrutura e Aspectos Regionais": & \\
\hline
\end{tabular}

Para comparar o que você considera importante entre os dois atributos em relação ao critério "Análise de Viabilidade Econômica":

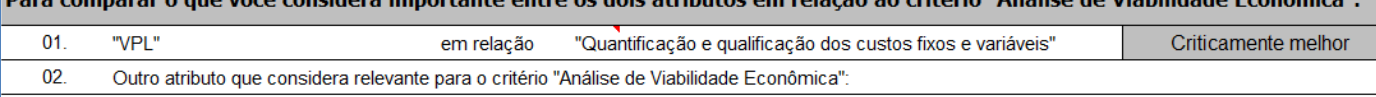

Para comparar o que você considera importante entre os dois atributos em relação ao critério "Capacidade e Eficiência Operacional":

\begin{tabular}{|cccc|c|}
\hline 01. & "Capacidade estática" & em relação & "Eficiência dos sistemas e linhas de processamento" & Criticamente melhor \\
\hline 02. & "Capacidade estática" & em relação & "Utilização (Giros de Armazém)" & \\
\hline 03. & "Capacidade estática" & em relação & "Qualidade do Produto" & \\
\hline 04. & "Utilização (Giros de Armazém)" & em relação & "Eficiência dos sistemas e linhas de processamento" & \\
\hline 05. & "Utilização (Giros de Armazém)" & em relação & "Qualidade do Produto" & \\
\hline 06. & "Qualidade do Produto" & em relação & "Eficiência dos sistemas e linhas de processamento" & \\
\hline 07. & Outro atributo que considera relevante para o critério "Capacidade e Eficiência Operacional": & \\
\hline
\end{tabular}


AFONSO, H. C. A. G. Analise dos custos de transporte da Soja Brasileira, 2006. Dissertação (mestrado) - Engenharia de Transportes, Instituto Militar de Engenharia, Rio de Janeiro, RJ.

ANANDA, J; HERATH, G. A critical review of multi-criteria decision making methods with special reference to forest management and planning. Ecological Economics, v.68, pág. 25352548, 2009.

ANDERSON, V. L; STUPELLO, B.; LEAL, M. B. S.; CARDOSO, J. S. L.; PINTO, M. M. $\mathrm{O}$. Avaliação da capacidade dos terminais de granéis agrícolas utilizados para escoamento da produção do centro-oeste brasileiro. Disponível em: <http://www.gestaonaval.org.br/Workshops.aspx?area=Logistica>, acesso em 20 de janeiro, 2011.

AZEVEDO, L. F; OLIVEIRA, T. P; PORTO, A. G; SILVA, F. S. A capacidade estática de armazenamento de grãos no Brasil. Anais ... XXVIII Encontro Nacional de Engenharia de Produção, 2008.

BALlOU, R. H. Gerenciamento da Cadeia de Suprimentos/ Logística Empresarial. 5.ed. Porto Alegre: Bookman, 2006.

BARFORD, M. B. An MCDA approach for the selection of bike projects bases on structuring and appraising activities. European Journal of Operational Reaserch. v. 218, pág. 810-818, 2011.

BATAGLIN, L. M. C.; BASILIO, T. L.; VIEIRA, J. G. V.; ROSSETTI, N. Avaliação de arranjo físico e custos logísticos na transferência de maquinário em uma unidade fabril. Revista Eletrônica Produção \& Engenharia, v. 3, n. 2, p. 300-308, Jan./Jun. 2013.

BELTON, V.; STEWART, T. J. Multiple Criteria Decision Analysis: an integrated approach 2.ed. Boston: Kluwer Academic Publishers, 2002.

BIAGI, J. D.; BERTOL, R.; CARNEIRO, M. C. Armazéns em Unidades centrais de Armazenamento (Cap. 3) In: LORINI, I.; MIIKE, L. H. \& SCUSSEL, V. M.; Armazenagem de Grãos, 2002.

BRASIL. Ministério da Agricultura, Pecuária e Abastecimento. Projeções do Agronegócio. 2009/2010 a 2019/2020. Disponível em: <http://www.agricultura.go v.br/arq_editor/file/MAIS\%20DESTAQUES/Proje\%C3\%A7\%C3\%B5es\%20Agroneg\%C3\% B3cio\%202009-2010\%20a\%202019-2020.pdf>. Acesso em: 28 de dezembro de 2010.

BRASIL. Ministério da Agricultura, Pecuária e Abastecimento. Projeções do Agronegócio. 2010/2011 a 2020/2021. Disponível em: <http://www.agricultura.gov.br/arq_edito r/file/Ministerio/gestao/projecao/PROJECOES\%20DO\%20AGRONEGOCIO\%20201011\%20a\%202020-21\%20-\%202_0.pdf>. Acesso em: 18 de julho de 2012.

BROOKER, D.B.; BAKKER-ARKEMA, F.W.; HALL, C.W. Drying and storage of grains and oilseeds. New York: Van Nostrand Reinhold, 1992.

CAIXETA-FILHO, J.V.; MARTINS, R.S. Gestão Logística do transporte de Cargas. São Paulo: Atlas, 2001.

CAMBOLAT, Y. B.; CHELST, K; GARG, N. Combining decision tree and MAUT for selection a country for a global manufacturing facility. Omega International Journal of Management Science, v. 35, pág. 312-325, 2005. 
CONAB - Companhia Nacional de Abastecimento (2006). Corredores de Escoamento da Produção Agrícola - Corredor do Rio Madeira. Disponível em http://www.conab.gov.br/conabweb/download/nupin/rio_madeira.pdf.

CONAB - Companhia Nacional de Abastecimento (2007). Corredores de Escoamento da Produção Agrícola - Corredor da BR-163. Disponível em <http://www.conab. CONAB: http://www2.conab.gov.br/projcdaconsulta/seleciona_armazem.asp

CRUZ, M. H. Utilização de uma metodologia de apoio a decisão na análise de outsourcing em uma empresa de metalurgia. Dissertação (mestrado) - Faculdade de Engenharia Mecânica, Universidade Estadual de Campinas, Campinas, SP. 2011.

D’ARCE, M. A. B. R. Pós colheita e Armazenamento de Grãos. Disponível em: < http://www.esalq.usp.br/departamentos/lan/pdf/Armazenamentodegraos.pdf >. Acesso em: 11 de junho, 2012.

DEVILLA, I. A. Projeto de Unidades Armazenadoras, 2004. Disponível em: < http://www.ebah.com.br>. Acesso em: 10 de junho, 2012.

ENSSLIN, S. R.; SOUZA, M. V.; ENSSLIN L. Um estudo de caso sobre gestão de portfólio de produtos e apoio à decisão multicritério, Produto \& Produção, Vol. 13, pp. 106-132, 2012.

FORMAN, E.; PENIWATI, K. Aggregating individual judgements and priorities with the Analytic Hierarchy Process, European Journal of Operational Research, Vol. 108, pp. 165169, 1998.

FREDERICO, S. Desvendando o agronegócio: financiamento agrícola e o papel estratégico do sistema de armazenamento do sistema de grãos. GEOUSP - Espaço e Tempo, São Paulo, No 27 , pp. $47-61,2010$.

FREITAS, A. L. P.; CORDEIRO, A. G. Priorização de requisitos para o desenvolvimento de software: uma abordagem multicritério utilizando AHP, Produto \& Produção, Vol. 12, n.2 pp. 87-107, 2011.

GAllardo, A. P.; STUPELlO, B.; GOldBERG, D. J. K.; CARDOSO, J. S. L.; PINTO, M. M. O. Avaliação da Capacidade de Infra-estrutura de Armazenagem para os Granéis Agrícolas Produzidos no Centro Oeste Brasileiro, 2010. Disponível em: <http://www.ipen.br>. Acesso em: 29 de dezembro, 2010.

GIL, A. C. Como elaborar projetos de pesquisa. 4 ed. São Paulo. Atlas, 2002.

HAJKOWICZ, S., A.; McDONALD, G., T.; SMITH, P., N. R. An evaluation of multiple objective decision support weighting techniques in natural resource management. Journal of Enviromental Planning and Management. v. 43, pág. 505-518, 2000.

HAYES R.; GARVIN, D. Managing as if Tommorow Mattered. Harvard Business Review, pp. 71-79, Mai.-Jun. 1982.

HORA, H. R. M.; MONTEIRO, G. T. R. ; ARICA, J. Confiabilidade em Questionários para Qualidade: Um Estudo com o Coeficiente alfa de Cronbach. Produto \& Produção, v. 11, n. 2, 24 jun. 2010.

KEENEY, R., L. Value-focused thinking: A Path to Creative Decision Analysis. Harvard University Press, Cambridge, 1992.

KEENEY, R., L. Value-focused thinking: Identifying decision opportunities and creating alternatives. European Journal of Operational Reaserch. v. 92, pág. 537-549, 1996. 
LACERDA FILHO, A. F. ; SILVA, Juarez de Souza e ; RESENDE, R. C. . Estruturas para armazenagem de grãos. In: Juarez de Souza e Silva. (Org.). Secagem e armazenagem de produtos agrícolas. 1ed.Viçosa: Editora Aprenda Fácil, 2000, v. 1, p. 325-344.

MARTINS, R. S.; REBECHI, D; PRATI, C. A.; CONTE, H. Decisões estratégicas na logística do agronegócio: compensação de custos transporte-armazenagem para a soja no estado do Paraná. Revista de Economia e Sociologia Rural, vol.9, n.1, pp. 53-78, 2005.

NETO, A. A. Finanças corporativas e valor. 3. ed. São Paulo: Atlas S.A., 2008. 716 p.

NOGUEIRA, M. C.; SILVA, C. A. C.; FAVARIN, J. V. R.; STUPELLO, B. Priorização de investimentos para o desenvolvimento logístico do Mato Grosso voltado para o escoamento da produção agrícola. Anais... XXII Congresso Nacional de Transporte Aquaviário, Construção Naval e Offshore, 2008.

NOGUEIRA JUNIOR, S.; TSUNECHIRO, A. Produção Agrícola e Infra-estrutura de Armazenagem no Brasil. Revista Informações Econômicas, São Paulo, v.35, n.2, fev, 2005.

OJIMA, A. L. R. O.; YAMAKAMI, A. Modelo de programação quadrática para análise da movimentação logística e comercialização da soja brasileira. Engenharia Agrícola Jaboticabal, v. 26, n. 2, p. 552-560, 2006.

OJIMA, A. L. R. O. (2006) "Perfil da Logística de Transporte de Soja no Brasil". Informações Econômicas, SP, v.36, n.1.

PARDALOS, P.M., SISKOS, Y., ZOPOUNIDIS, C. Advances in Multicriteria Analysis. Dordrecht: Kluwer Academic Publishers, 1995.

PASIN, J. A. B. (2007) A Logística de Exportação da Soja em Grãos de Mato Grosso. Revista do BNDES, Rio de Janeiro, v. 14, n. 27, p. 195-212, jun. 2007.

PINAZZA, L. A. Cadeia Produtiva da Soja: Volume 2, 2007. Disponível em: < http://www.agricultura.gov.br/>. Acesso em: 28 de dezembro de 2010.

ROY, B., BOUYSSOU, D., 1993. Aide Multicritère à la Décision: Méthodes et Cas. Economica, Paris.

SAATY, T.L. The Analytic Hierarchy Process, New York: McGraw Hill. International, 1980.

SALOMON, V. A.P. Auxílio à decisão para a adoção de políticas de compras, Produto \& Produção, Vol. 6, n.1 pp. 01-08, 2002.

SILVA, M. S.; MENEZES, T. M. (2008). Corredor de Escoamento Noroeste: Alternativa Logística para Produtores Agrícolas das Regiões Centro e Norte do Estado do Mato Grosso. Revista em Agronegócios e Meio Ambiente, v.1, n.1, p.37-44.

SOUZA FILHO, H. M.; GAUNZIROLI, C. E.; BUAINAIN, A. M. Metodologia para estudos das relações de mercado em sistemas agroindustriais. 2008. Disponível em: < http://www.iica.org.br/Docs/Publicacoes/Agronegocio/Metodologia_de_Sistemas_Agroindust riais.pdf $/>$. Acesso em: 12 de fevereiro de 2012.

TRIGEORGIS, L.: Real Option and Interactions with Financial Flexibility, Financial Management, pp. 202-224, 1993.

YANG, J; LEE, H. An AHP decision model for facility location selection", Facilities, Vol. 15, pp.241 - 254, 1997.

ZANCHET, A. Depósitos Mercantis: um estudo de práticas contábeis dos depositários na comercialização de produtos agrícolas no estado do Paraná. Dissertação (mestrado) Faculdade de Economia e Administração, Universidade de São Paulo, São Paulo, SP. 2004. 